\title{
An analytical solution for the exhumation of an orogenic wedge and a comparison with thermochronology data
}

\author{
Elco Luijendijk ${ }^{1,2}$, Leo Benard ${ }^{3}$, Sarah Louis ${ }^{1,2}$, Christoph von Hagke ${ }^{2,4}$, and Jonas Kley ${ }^{1}$ \\ ${ }^{1}$ Department of structural geology and geodynamics, University of Göttingen, Goldschmidtstrasse 3, 37077, Göttingen, \\ Germany \\ ${ }^{2}$ Geological Institute, RWTH Aachen University, Wüllnerstr. 2, 52062, Aachen, Germany \\ ${ }^{3}$ Mathematisches Institut, University of Göttingen, Bunsenstraße 3-5, 37073, Göttingen, Germany \\ ${ }^{4}$ Department of Geography and Geology, University of Salzburg, Hellbrunnerstraße 34/III, 5020, Salzburg, Austria,
}

Correspondence: Elco Luijendijk (elco.luijendijk@ posteo.net)

\begin{abstract}
Thermochronology data is key for quantifying the exhumation history and dynamics of mountain belts. Here we present a new analytical solution for the steady-state exhumation of an orogenic wedge that undergoes transport along a basal detachment, uniform internal deformation, basal and frontal accretion. The solution predicts an increase in exhumation towards the interior of the wedge, with the rate of increase dependent on the degree of internal deformation. Application of the solution to a cross section in the Himalayas shows that in spite of its simplicity the solution provides a good fit to thermochronology data, with a coefficient of determination $\left(\mathrm{R}^{2}\right)$ of 0.75 . This implies that, although the solution does not capture the effects of individual faults and folds, at a large scale deformation can be described by uniform compression and transport. The results also imply that this part of the Himalayas may be in steady-state. The equations presented here can be used to quantify exhumation, deformation and shortening rates in mature orogens that are in steady-state.
\end{abstract}

\section{Introduction}

Thermochronology has increased our knowledge of the thermal and exhumation history of mountain belts (Reiners and Brandon, 2006). Numerical models that include faulting, erosion and heat flow enable the use of thermochronology data to quantify deformation (ter Voorde et al., 2004; Lock and Willett, 2008; Braun et al., 2012). Such models have for example been used to quantify the geometry and slip rates of major faults (Herman et al., 2010; Robert et al., 2011). The combination of numerical models and deformation histories derived from balanced cross-sections has enabled more detailed reconstructions of deformation history (Erdös et al., 2014; McQuarrie and Ehlers, 2015). However, one drawback of using numerical models for the interpretation of thermochronometers in orogens is that they require significant resources in terms of computational cost, geological data and research time. Furthermore these approaches rely on the knowledge of the location of faults, which may not be complete and depends on the quality of geological mapping and exposure. In addition, the models often assume that the fault blocks in between behave as rigid blocks, and may not include internal deformation of faults blocks by small-scale faults and folds inside these blocks. 
https://doi.org/10.5194/se-2021-22

Preprint. Discussion started: 15 March 2021

(c) Author(s) 2021. CC BY 4.0 License.

\section{(c) (1)}

Analytical solutions could offer an alternative as they require few computational resources and provide insight into the relation between input parameters and results without having to resort to computationally expensive sensitivity analyses. However, to our knowledge no analytical solutions exist for the relation between deformation and exhumation of mountain belts. Interestingly, the problem of quantifying exhumation is somewhat analogous to the quantification of groundwater age, which deals with groundwater moving downward after infiltration instead of rock particles moving up to the surface. Analytical solutions for groundwater age have been published (Vogel, 1967), which suggests that the description of exhumation may be mathematically tractable.

Here we aim to develop a new closed-form analytical solution for the exhumation of an orogenic wedge that is in steadystate. The solution aims to include the main deformation mechanisms of orogenic wedges, internal deformation of the wedge, transport along a basal detachment, basal accretion and frontal accretion. In contrast to most numerical approaches we aim to represent a relatively simple system in which the orogenic wedge undergoes pervasive internal deformation, and we do not resolve individual faults. We evaluate how well this solution can represent thermal and deformation history by applying the equation to a a well-studied cross-section in the Himalayas (Long et al., 2012; Coutand et al., 2014; McQuarrie and Ehlers, 2015), and by using the calculated exhumation histories to calculate thermochonometer ages and compare these to published data.

\section{Conceptual model}

Previous research has shown that at a first order the cross-sectional geometry of the brittle part of many orogens (i.e. until the basal detachment becomes aseismic, typically at $300^{\circ} \mathrm{C}$ ) can be approximated by a critical wedge (Buiter, 2012). After some amount of convergence the orogenic wedge reaches a steady-state that is formulated by the critical wedge theory (Davis et al., 1983; Chapple, 1978; Dahlen et al., 1984), whereby the topography of the wedge is a function of balance between the compressional force, the friction along a basal detachment and the gravitational force. Steady-state is maintained by the incorporation of new material by frontal (Platt, 1986), and basal accretion (Van Gool and Cawood, 1994), and the loss of material by erosion at the land surface. In addition the rocks in the wedge itself deform as a result of compressional forces.

Here we derive a model that describes the motion of rock particles inside an orogenic wedge that is in steady-state, i.e., the geometry of the wedge is fixed and the flow of material into the wedge is balanced by erosion. The model covers three mechanisms for the deformation of an orogenic wedge: 1) Transport of the wedge along a basal detachment, 2) internal deformation of the wedge and 3) frontal and basal accretion. These three processes are shown schematically in Figure 1. The geometry of the wedge and the parameters that are used in this manuscript are shown in Figure 2. The symbols in the figure are defined in Table 1.

Here we briefly summarize the way these processes are represented in the analytical solution that we derive below. The motion of material inside the wedge is described using the tip of the wedge as a fixed reference point.

1. Transport of the wedge along a basal detachment results in a uniform motion of the material in the wedge upward and towards the tip of the wedge, with velocity vectors parallel to the wedge. Because the shape of the wedge is kept constant, 
https://doi.org/10.5194/se-2021-22

Preprint. Discussion started: 15 March 2021

(c) Author(s) 2021. CC BY 4.0 License.

(c) (i)

55

transport along the detachment means that material is added on the right hand side of the wedge, and removed at the same rate at the top of the wedge. The material added at the right hand side and removed from the top of the wedge due to detachment transport are shown by blue and yellow areas respectively in Fig. 2a.

2. The internal deformation of the wedge is modelled as a uniform compression of the material inside the wedge. This is the most simple way to represent the internal deformation of the wedge that in reality is accommodated by faulting and folding inside the wedge. The equations are based on the assumption that each rock particle in the wedge is compressed horizontally by exactly the same amount. This causes an expansion by the same amount for each particle. Note that we assume here that there is no volume loss. These assumptions lead to a total amount of expansion in the wedge that increases linearly from 0 at the tip of the wedge to a maximum at the right hand-side of the wedge. The linear correlation between wedge thickness and exhumation is the result of more rocks being available to compress in a thicker wedge. The shape of the wedge remains constant, and therefore the deformation caused by compression is compensated by adding material on the right hand side of the wedge and by eroding an equal amount of material from the top of the wedge (Fig. 2b).

3. Frontal and basal accretion add material to the front and the base of the wedge, as shown in Fig $2 \mathrm{c}$ and Fig. 2d, respectively. Given that we use the fixed geometry of the wedge as a reference frame, this causes a movement of rock particles inside the wedge to the right and upward. Note that by itself frontal accretion as described in our simple conceptual model will generate an unrealistic addition of material to the wedge above the land surface (Fig. 2c). Therefore frontal accretion should only be used in combination with rates of detachment transport, compression or basal accretion that are sufficient to balance out the material added with erosion at the land surface.

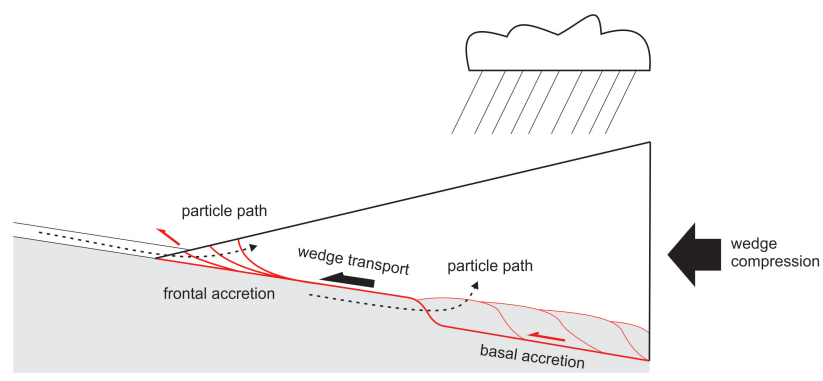

Figure 1. Conceptual model of an orogenic wedge showing the material transport and deformation mechanisms that act on the wedge.

\section{Development of the analytical solution}

We first develop solutions for the velocity of rock particles in the wedge (section 3.1), and subsequently use these equations to develop expressions for the trajectories of rock particles (section 3.2). We initially develop separate solutions for the transport of the wedge and basal and frontal accretions, and a solution for the velocity field due to compression of the wedge. The latter 


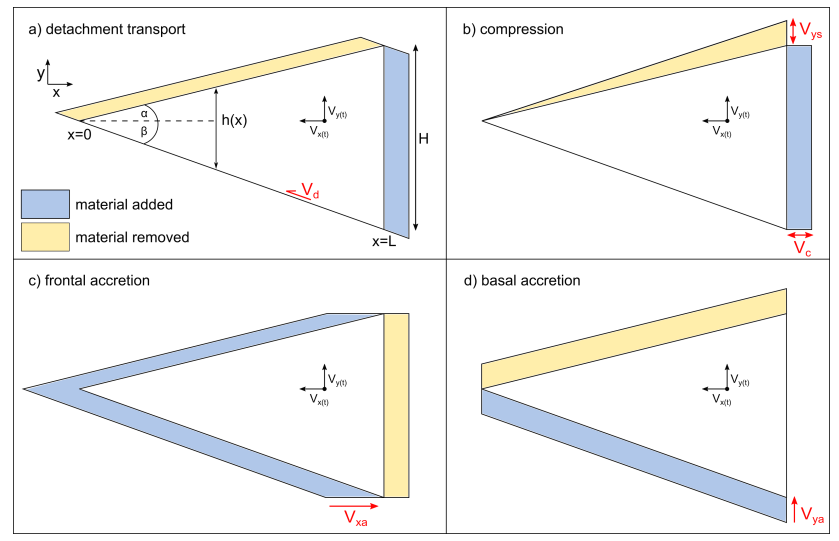

Figure 2. Conceptual model of an orogenic wedge as used in this study. The four panels show the four processes represented in the analytical solution, detachment transport (panel a), internal deformation represented by uniform compression (panel b), frontal (panel c) and basal accretion (panel d). The symbols listed in Table 1 .

Table 1. Symbols and units

\begin{tabular}{|c|c|c|}
\hline symbol & unit & description \\
\hline $\mathrm{L}$ & $\mathrm{m}$ & width of the wedge \\
\hline$\alpha$ & $\mathrm{m} \mathrm{m}^{-1}$ & the slope of the land surface \\
\hline$\beta$ & $\mathrm{m} \mathrm{m}^{-1}$ & the slope of the bottom of the wedge \\
\hline $\mathrm{H}$ & $\mathrm{m}$ & maximum height of the wedge \\
\hline$h(x)$ & $\mathrm{m}$ & height of the wedge at any coordinate $\mathrm{x}$ \\
\hline$b$ & $\mathrm{~m}$ & elevation of the bottom of the wedge above a reference point \\
\hline$v_{x a}$ & $\mathrm{~m} \mathrm{~s}^{-1}$ & horizontal velocity of particles due to basal and frontal accretion \\
\hline$v_{y a}$ & $\mathrm{~m} \mathrm{~s}^{-1}$ & vertical velocity of particles due to basal and frontal accretion \\
\hline$v_{d}$ & $\mathrm{~m} \mathrm{~s}^{-1}$ & horizontal transport velocity of the wedge along a basal detachment \\
\hline$v_{c}$ & $\mathrm{~ms}^{-1}$ & horizontal compression velocity of the wedge \\
\hline$v_{y s}$ & $\mathrm{~m} \mathrm{~s}^{-1}$ & vertical particle velocity at the top of the wedge \\
\hline$v_{x}$ & $\mathrm{~m} \mathrm{~s}^{-1}$ & horizontal particle velocity in the wedge \\
\hline$v_{y}$ & $\mathrm{~m} \mathrm{~s}^{-1}$ & vertical particle velocity in the wedge \\
\hline
\end{tabular}

is mathematically the most challenging process to represent. Subsequently we combine the solutions to first derive a simplified and finally a full analytical solution for particle trajectories inside an orogenic wedge resulting from compression, transport along a detachment and accretion, which is given by equations 10 and 12. The full derivation of the solutions is provided in appendix A for the equations of particle velocity and appendix B for the equations for particle trajectories. The solutions are 
https://doi.org/10.5194/se-2021-22

Preprint. Discussion started: 15 March 2021

(c) Author(s) 2021. CC BY 4.0 License.

Table 2. Model parameters for the examples shown in sections 3 and 4

\begin{tabular}{lll}
\hline parameter & value, parameter set 1 & value, parameter set 2 \\
\hline $\mathrm{L}$ & $200 \mathrm{~km}$ & $200 \mathrm{~km}$ \\
$\alpha$ & $0.05 \mathrm{~m} \mathrm{~m}^{-1}$ & $0.05 \mathrm{~m} \mathrm{~m}^{-1}$ \\
$\beta$ & $-0.15 \mathrm{~m} \mathrm{~m}^{-1}$ & $-0.15 \mathrm{~m} \mathrm{~m}^{-1}$ \\
$v_{x a}$ & $0 \mathrm{~m} \mathrm{a}^{-1}$ & $1 \times 10^{-3} \mathrm{~m} \mathrm{a}^{-1}$ \\
$v_{y a}$ & $0 \mathrm{~m} \mathrm{a}^{-1}$ & $1 \times 10^{-4} \mathrm{~m} \mathrm{a}^{-1}$ \\
$v_{d}$ & $-2 \times 10^{-3} \mathrm{~m} \mathrm{a}^{-1}$ & $0 \mathrm{~m} \mathrm{a}^{-1}$ \\
$v_{c}$ & $-2 \times 10^{-3} \mathrm{~m} \mathrm{a}^{-1}$ & $-2 \times 10^{-3} \mathrm{~m} \mathrm{a}^{-1}$ \\
\hline
\end{tabular}

demonstrated for two example cases, which represent a wedge undergoing compression and transport along a basal detachment and a wedge undergoing compression and basal and frontal accretion. The parameters for these example cases are shown in Table 2. The solution is also applied to a case study in the Himalayas, which is discussed in section 5.

\section{$85 \quad 3.1$ Rock particle velocity}

The combined horizontal and vertical particle velocity due to transport along a detachment and accretion is denoted as $\mathrm{v}_{\mathrm{xt}}$ and $\mathrm{v}_{\mathrm{yt}}$, respectively:

$v_{x t}=v_{d}+v_{x a}$

$v_{y t}=\beta v_{x}+v_{y a}$

90 The horizontal and vertical components of the rock particle velocity due to compression are given by:

$v_{x}=\frac{x}{L} v_{c}$

and

$v_{y c}=v_{n}(\epsilon y+\zeta x)$

where $\epsilon$ and $\zeta$ are defined as:

$95 \epsilon=\left(-2-\frac{\beta}{\alpha-\beta}\right)$ 
https://doi.org/10.5194/se-2021-22

Preprint. Discussion started: 15 March 2021

(c) Author(s) 2021. CC BY 4.0 License.

(c) (i)

$\zeta=\left(2 \beta+\frac{\alpha \beta}{\alpha-\beta}\right)$

and $\mathrm{v}_{\mathrm{n}}$ denotes normalized compression velocity, which is defined as:

$v_{n}=\frac{v_{c}}{L}$

The total velocity of rock particles can be found by combining the velocity due to transport (eqs. 1 and 2) and the velocity due to compression (eqs. 3 and 4). For the horizontal component of velocity this yields:

$v_{x}=v_{x c}+v_{x t}=v_{n} x+v_{x t}$

And for the vertical component of velocity this yields:

$v_{y}=v_{n}(\epsilon y+\zeta x)+v_{y t}$

The combined velocity fields are shown in figure 3 and Fig. 4 for an example orogenic wedge. The parameters are shown in

Table 2. The first case shows a wedge undergoing compression and transport along a detachment, which results in an overall rock particle motion towards the tip of the wedge and upward. Fig. 4 shows the velocity in a wedge undergoing compression and accretion, which results in an overall particle motion towards the interior of the wedge and upward. 
https://doi.org/10.5194/se-2021-22

Preprint. Discussion started: 15 March 2021

(c) Author(s) 2021. CC BY 4.0 License.

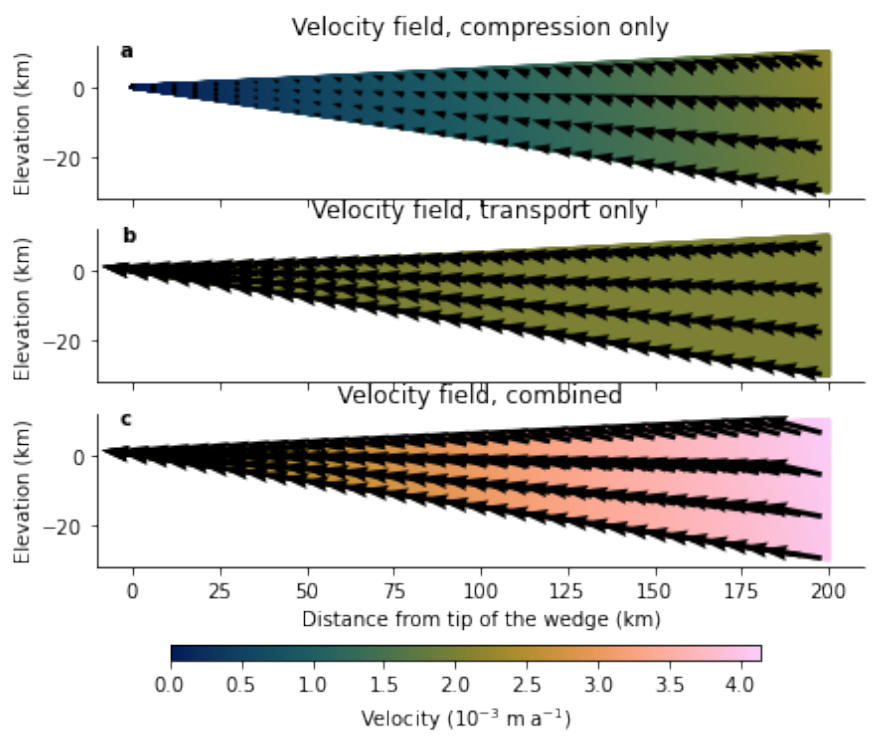

Figure 3. Particle velocity inside a wedge undergoing internal deformation and transport along a basal detachment, using parameter set 1 in Table 2. Panel a hows the velocity field resulting from compression of the wedge, panel b shows the velocity field resulting from transport of particles inside the wedge and panel c shows the velocity field due to both compression and transport.

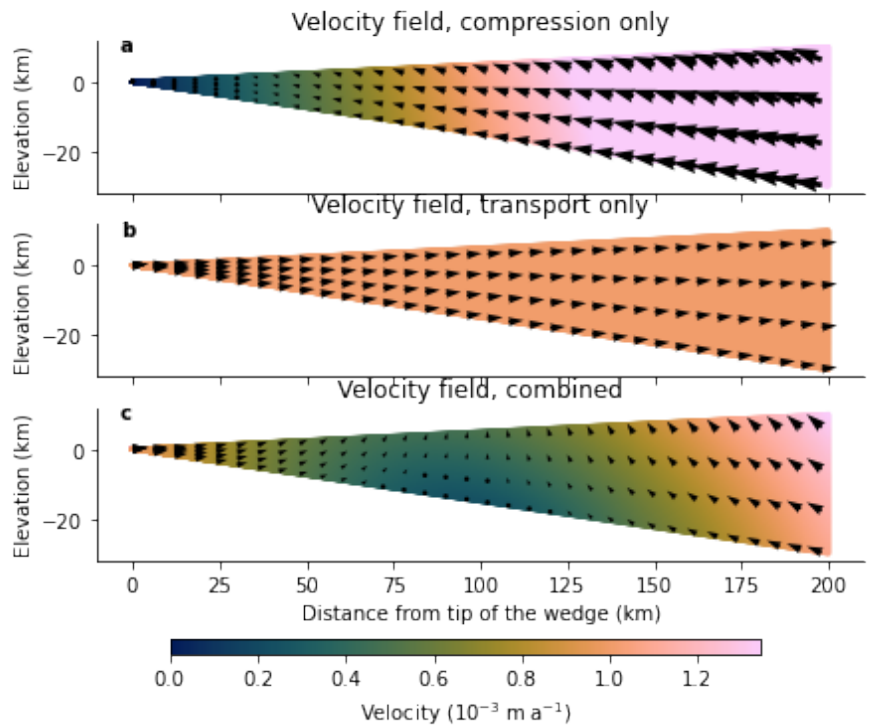

Figure 4. Particle velocity inside a wedge undergoing internal deformation and basal and frontal accretion, using parameter set 2 in Table 2. Panel a hows the velocity field resulting from compression of the wedge, panel b shows the velocity field resulting from transport of particles inside the wedge and panel c shows the velocity field due to both compression and transport. 
https://doi.org/10.5194/se-2021-22

Preprint. Discussion started: 15 March 2021

(c) Author(s) 2021. CC BY 4.0 License.

(c) (i)

\subsection{Particle trajectories}

The equation for the horizontal position of particles over time follows from integration of the velocity equations as:

$110 x=\left(x_{0}+\frac{v_{x t}}{v_{n}}\right) e^{v_{n} t}-\frac{v_{x t}}{v_{n}}$

Where $\mathrm{x}_{0}$ is the horizontal position of the rock particle at $t=0$.

The first solution for the vertical position is a simplified solution, where we take the depth below the surface for compression and for transport and add these two to get an expression for depth over time. This results in the following approximate solution for the depth of rock particles (d) over time:

115

$d=-v_{y t} t+(\alpha-\beta) x_{0}\left(e^{v_{n} t}-e^{\epsilon v_{n} t}\right)$

Combining the expression for $\mathrm{x}$ (eq. 10) and the vertical velocity (eq. 9) and integration of the equation yields the full solution of the vertical particle position in the wedge:

$y=\left(\alpha x_{0}+\beta\left(x_{0}+\frac{v_{x t}}{v_{n}}\right)\left(e^{v_{n}(1-\epsilon) t}-1\right)-\frac{v_{y t}-\zeta v_{x t}}{v_{n} \epsilon}\left(e^{-v_{n} \epsilon t}-1\right)\right) e^{v_{n} \epsilon t}$

This equation describes the vertical position of rock particles in a wedge $(\mathrm{y})$ as a function of time $(\mathrm{t})$, the initial position $\left(\mathrm{x}_{0}\right)$, the slope of the land surface $(\alpha)$ and the basal detachment $(\beta)$, the normalized compression velocity $\left(\mathrm{v}_{\mathrm{n}}\right)$, which is a function of the horizontal compression $\left(\mathrm{v}_{\mathrm{c}}\right)$ and the length of the wedge $(\mathrm{L})\left(v_{n}=v_{c} / L\right)$, the horizontal $\left(\mathrm{v}_{\mathrm{xt}}\right)$ and vertical $\left(\mathrm{v}_{\mathrm{yt}}\right)$ transport velocity, which are a function of basal and frontal accretion velocity and transport velocity along the basal detachment (eqs. 1 and 2) and the geometry parameters $\epsilon$ (eq. 5) and $\zeta$ (eq. 6), which are functions of $\alpha$ and $\beta$.

This equation can be adjusted to yield an expression for the depth of rock particles below the land surface (d), instead of the vertical position:

$d=\alpha x_{0}-\left(\alpha x_{0}+\beta\left(x_{0}+\frac{v_{x t}}{v_{n}}\right)\left(e^{v_{n}(1-\epsilon) t}-1\right)-\frac{v_{y t}-\zeta v_{x t}}{v_{n} \epsilon}\left(e^{-v_{n} \epsilon t}-1\right)\right) e^{v_{n} \epsilon t}$

\section{Validation of analytical solutions}

The simplified analytical solution for rock particle trajectories (eqs. 10 and 11) and the full solution (eq. 10 and 12) were verified using numerical particle tracking using the velocity fields described by the equations for particle velocity (eqs. 8 and 9). A number of particles were placed at the surface at $t=0$. The velocity of these particles were calculated using these equations. In turn the velocities were used to calculate new particle positions at $t-\Delta t$ where $\Delta t$ is a time increment and the procedure was repeated. This procedure provides a history of depth versus time for each particle that can be used to verify the 
https://doi.org/10.5194/se-2021-22

Preprint. Discussion started: 15 March 2021

(c) Author(s) 2021. CC BY 4.0 License.

(c) (i)

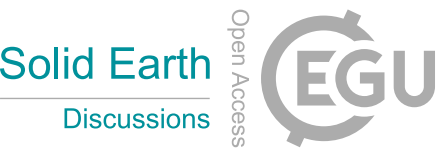

analytical solutions for particle depth over time, i.e. to explore whether the solution is consistent with the velocity fields that were derived in section 3.1.

135 The comparison between the numerical model and the simplified and full analytical solutions shows that the full solution matches the numerical results perfectly for example cases dominated by transport along a basal detachment (Figs. 5) and basal and frontal accretion (Fig. 6). The maximum difference of the full solution and the numerical results is $0.12 \%$. The simplified solution deviates from the numerical and the full solution for both cases. The maximum difference with the full solution is 30 $\%$. The error increases with depth (Fig. 5d, 6d). This means that the simplified solution may still be useful to predict particle

140 trajectories for the more shallow and low-temperature domains of the wedge. However, this is not the case for samples that are close to the tip of the wedge for models with significant basal and frontal accretion (Fig. 6d), where the deviation from the full solution is relatively large. 
https://doi.org/10.5194/se-2021-22

Preprint. Discussion started: 15 March 2021

(c) Author(s) 2021. CC BY 4.0 License.
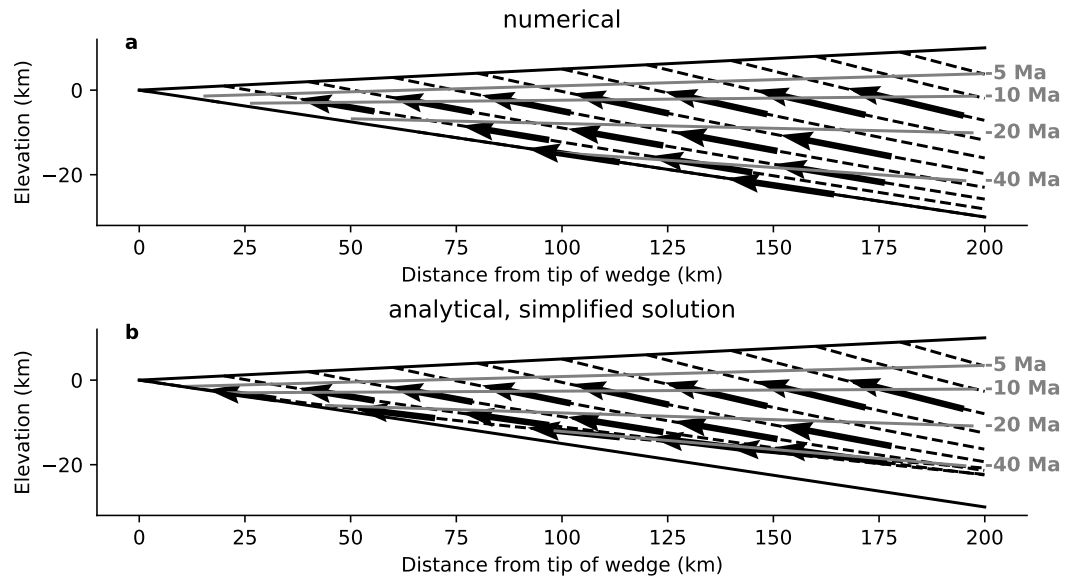

analytical, full solution
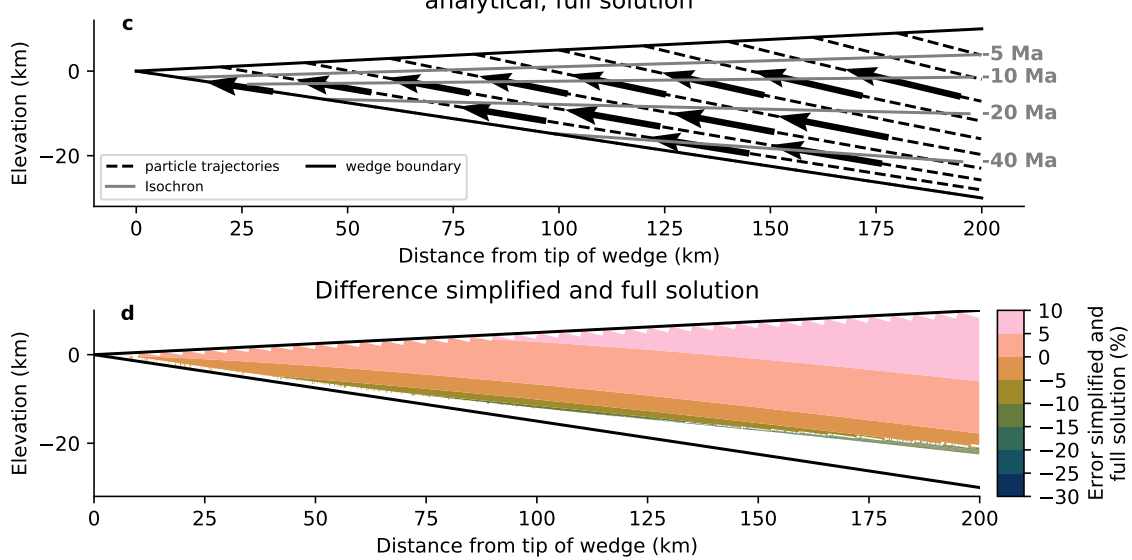

Figure 5. Comparison of analytical and numerical solutions for particle trajectories in a wedge undergoing internal deformation and transport along a basal detachment. Panel a shows the numerical solution for particle trajectories, panel b shows the simplified analytical solution (eq. 10 and 11), panel c shows the full solution (eq. 10 and 12), and panel d shows the difference between the simplified and full solution. The particle trajectories were calculated using parameter set 1 in Table 2. 
https://doi.org/10.5194/se-2021-22

Preprint. Discussion started: 15 March 2021

(c) Author(s) 2021. CC BY 4.0 License.
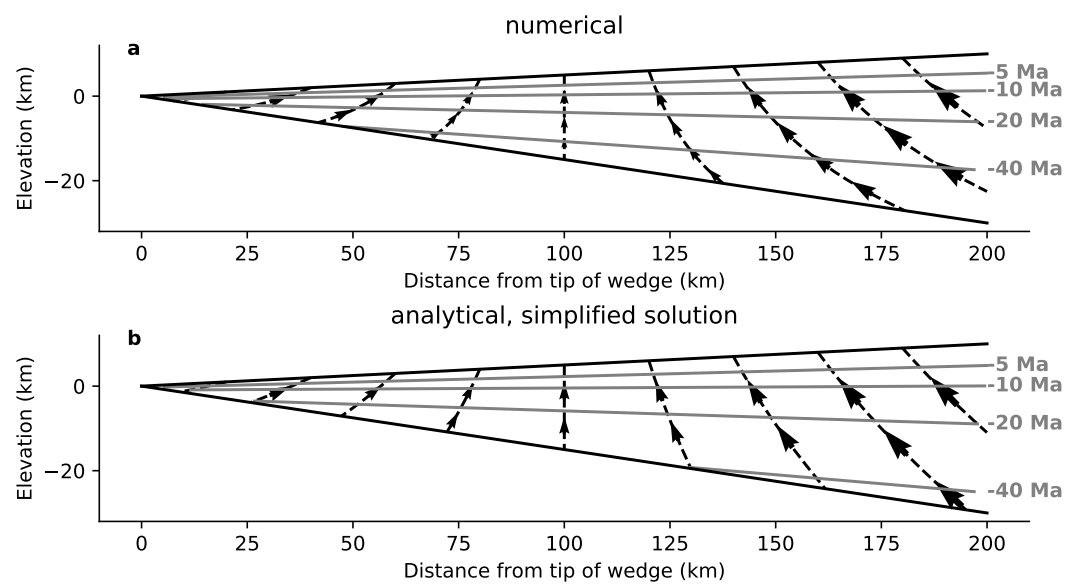

analytical, full solution

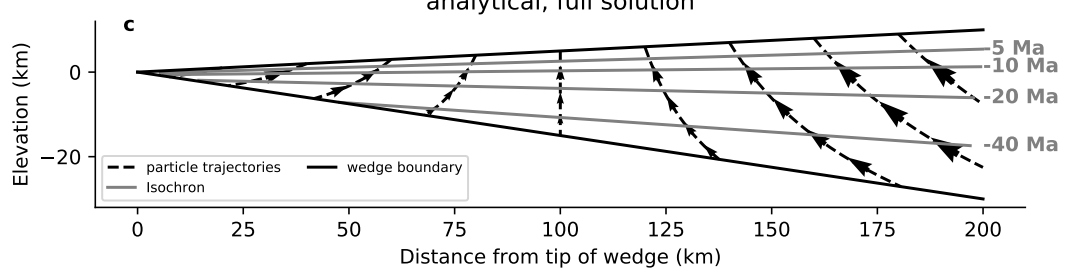

Difference simplified and full solution

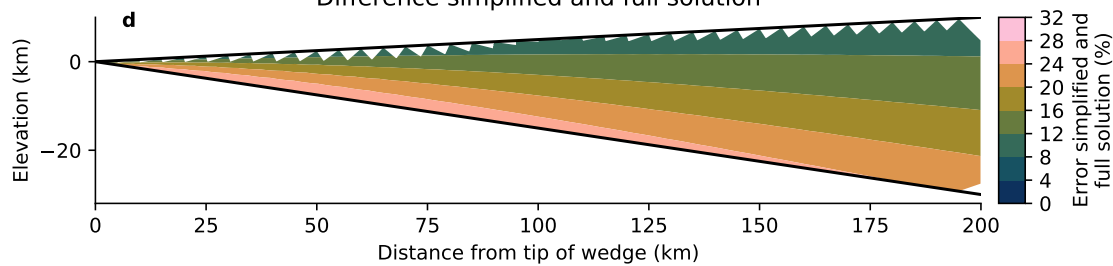

Figure 6. Comparison of analytical and numerical solutions for particle trajectories in a wedge undergoing internal deformation and basal and frontal accretion. Panel a shows the numerical solution for particle trajectories, panel b shows the simplified analytical solution (eq. 10 and 11), panel c shows the full solution (eq. 10 and 12), and panel d shows the difference between the simplified and full solution. The particle trajectories were calculated using parameter set 2 in Table 2. 
https://doi.org/10.5194/se-2021-22

Preprint. Discussion started: 15 March 2021

(c) Author(s) 2021. CC BY 4.0 License.

(c) (i)

\section{Application to the exhumation of a mountain belt}

\subsection{Introduction}

We used equations 10 and 12 to calculate particle trajectories for a case study based on a published cross-section in the Himalayas, the Kuru-Chu cross-section (Long et al., 2012; Coutand et al., 2014; McQuarrie and Ehlers, 2015). The crosssection is located in Bhutan in the central Himalayas and runs perpendicular to the strike of the Himalayas and the main faults. The cross-section and the wedge geometry that was adopted based on this cross-section are shown in Fig. 7. The cross-section was chosen because of the abundance of thermochronology data that covers both low-temperature (apatite fission track) and high temperature (muscovite Ar-Ar) thermochronology. In addition, the high convergence rate in the Himalayas makes it likely that exhumation is governed by the processes that are represented in the equations that we derived. Comparison of long-term (i.e. million year), intermediate (100-10 kyrs) and short term (yrs) erosion rate estimates indicates that the study area is in steady state (Ganti et al., 2016). This implies that other processes such as glacial erosion and isostatic compensation that are not captured by the equations are likely to be relatively minor. Note that the goal here is not to provide a detailed geological case study, but to demonstrate the use of the equation to calculate deformation and exhumation rates.

\subsection{Wedge geometry}

The tip of the wedge was based on the location of the southernmost thrust fault in this part of the Himalayas, the main frontal thrust. The geometry of the wedge is based on published geological cross-sections (Long et al., 2012; Coutand et al., 2014; McQuarrie and Ehlers, 2015), with a surface slope $(\alpha)$ of $0.034 \mathrm{~m} \mathrm{~m}^{1}$, an average slope of the basal detachment $(\beta)$ of -0.17 $\mathrm{m} \mathrm{m}^{1}$ and a total length of $200 \mathrm{~km}$.

\subsection{Thermochronology data and cooling ages}

There is a large set of thermochronometer data available for the cross-section, including 17 apatite fission track samples (Grujic et al., 2006; Long et al., 2012; Coutand et al., 2014), 23 zircon (U-Th)/He samples (Long et al., 2012; Adams et al., 2013) and 8 muscovite Ar-Ar samples (Long et al., 2012).

Particle trajectories were converted to thermal history using a uniform geothermal gradient of $15 \mathrm{C} \mathrm{km}^{-1}$, which is based on a gradient of 10 to $20 \mathrm{C} \mathrm{km}^{-1}$ reported by Coutand et al. (2014). Surface temperature was calculated using a surface temperature at sea level of $24{ }^{\circ} \mathrm{C}$ and a atmospheric lapse rate of $7{ }^{\circ} \mathrm{C} \mathrm{km}^{-1}$ (Coutand et al., 2014). Cooling ages were calculated using the thermal history and assumed resetting temperatures of $110{ }^{\circ} \mathrm{C}, 180{ }^{\circ} \mathrm{C}$ and $325{ }^{\circ} \mathrm{C}$ for the apatite fission track, for zircon (U-Th)/He and muscovite Ar-Ar thermochronometers, respectively (McQuarrie and Ehlers, 2018). Note that we aim for a simple model setup and do not include more complex calculation based either on a more formal definition of cooling ages (Dodson, 1973; Fox et al., 2014) or fission track annealing models or diffusion models of He or Ar, which we reserve for follow up work. Ages for samples that originated in the foreland of the wedge and that did not reach resetting temperatures in the wedge were calculated using an assumed exhumation rate of $1 \times 10^{-4} \mathrm{~m} \mathrm{a}^{-1}$. This was done to give these 
https://doi.org/10.5194/se-2021-22

Preprint. Discussion started: 15 March 2021

(c) Author(s) 2021. CC BY 4.0 License.

(c) (i)

samples arbitrary high ages that approximate the typically higher ages found in foreland basins of orogenic wedges. Note that we did not calculate ages for samples that originated in the hinterland of the wedge, because it is difficult to make assumptions about their thermal history and initial age prior to entering the wedge.

\subsection{Model calibration and parameter space exploration}

The optimal values of the model parameters $\mathrm{v}_{\mathrm{c}}, \mathrm{v}_{\mathrm{d}}, \mathrm{v}_{\mathrm{xa}}, \mathrm{v}_{\mathrm{ya}}$ were found using the downhill simplex algorithm (Nelder and Mead, 1965), as implemented in the Python module scipy (Virtanen et al., 2020), to minimize the mean absolute error (MAE) of the calculated thermochronometer ages.

In addition to model calibration we also ran a set of models with different parameter combinations to explore the sensitivity of the model fit to the parameter values. For the parameters $v_{c}$ and $v_{d}$ the values were varied from the calibrated value $-4 \times 10^{-3}$ $\mathrm{m} \mathrm{a}^{-1}$ to $+4 \times 10^{-3} \mathrm{~m} \mathrm{a}^{-1}$ with steps of $1 \times 10^{-3} \mathrm{~m} \mathrm{a}^{-1}$. For parameter $\mathrm{v}_{\mathrm{xa}}$ we tested the calibrated value plus $1 \times 10^{-3}$ $\mathrm{m} \mathrm{a}^{-1}$ and $2 \times 10^{-3} \mathrm{~m} \mathrm{a}^{-1}$, respectively, and for $\mathrm{v}_{\text {ya }}$ we evaluated the calibrated value plus $1 \times 10^{-4} \mathrm{~m} \mathrm{a}^{-1}$ and $2 \times 10^{-4}$ $\mathrm{m} \mathrm{a}^{-1}$, respectively.

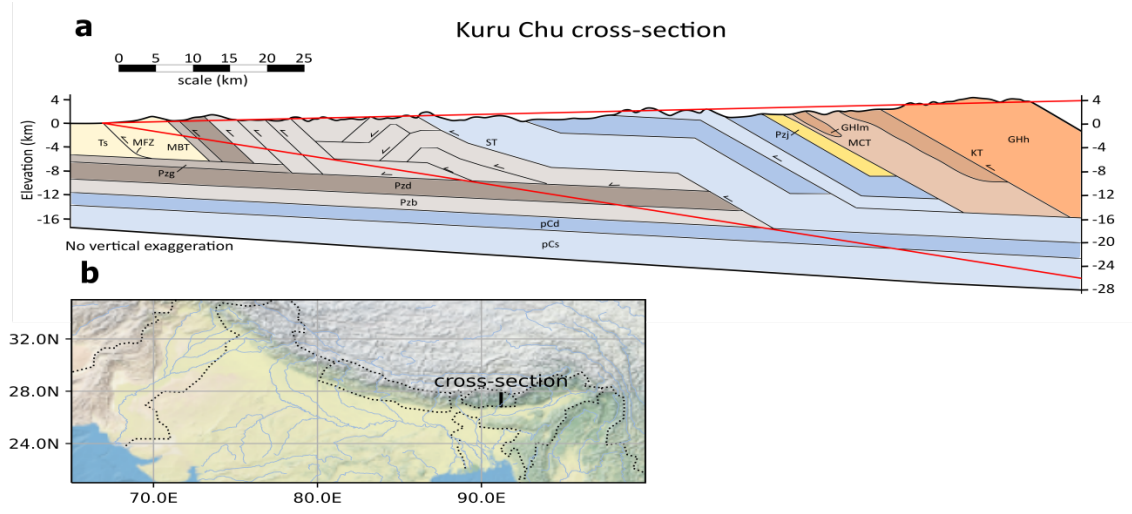

Figure 7. Geological cross-section in Bhutan that was used as a case study and the geometry of the wedge as used for the calculation of particle trajectories and exhumation (panel a) and location of the cross-section (panel b). The cross-section was modified from Long et al. (2012). MFT denotes the main frontal thrust, MBT the main boundary thrust, MCT denotes the main central thrust and KT the Kakhtang thrust. The tectonostratigraphic units are denoted as follows: GHh: Greater Himalaya GHm: Greater Himalaya metasedimentary unit, Pzj: Jaishinda formation, pCs: Shumar formation, pCd: Daling formation, Pzb: Baxa group, Pzd: Diuiri Formation, Pzg: Gondwana succession, Ts: Siwalik Group.

\subsection{Results}

The the best-fit parameter values show a relatively good fit of the calculated thermochronometer ages to the measured ages in the cross-section (Fig. 8a), with a coefficient of determination of 0.75 . The calibrated parameters values indicate that transport 
https://doi.org/10.5194/se-2021-22

Preprint. Discussion started: 15 March 2021

(c) Author(s) 2021. CC BY 4.0 License.

\section{(c) (1)}

along the basal detachment and internal deformation are equally important mechanisms driving exhumation of the wedge, with a calibrated value of the transport $\left(\mathrm{v}_{\mathrm{d}}\right)$ and compression velocity $\left(\mathrm{v}_{\mathrm{c}}\right)$ of $5.0 \times 10^{-3} \mathrm{~m} \mathrm{a}^{-1}$ and $4.8 \times 10^{-3} \mathrm{~m} \mathrm{a}^{-1}$, respectively (Table 3). Frontal and basal accretion play an insignificant role in this cross-section, with a best-fit value of $1.7 \times 10^{-6} \mathrm{~m} \mathrm{a}^{-1}$ for the horizontal component $\left(\mathrm{v}_{\mathrm{xa}}\right)$ of the accretion vector, and a value of 0.0 for the vertical component $\left(\mathrm{v}_{\mathrm{ya}}\right)$.

The exploration of parameter space show a relatively small area with a good fit (Fig. 9). A reduction in detachment transport velocity can to some extent be taken up by an increase in compression velocity and vice versa. However, both processes results in fundamentally different exhumation and cooling age curves, with a straight line for models dominated by transport over a detachment only (Fig. 10a, b), and a curved line for models that include compression (Fig. 10c, d). This means that the degree of curvature of cooling ages along a cross-section and the rate of decrease in ages towards the interior of the wedge can be used to quantify the rate of internal deformation of orogenic wedges.

Note that Coutand et al. (2014) report that the geothermal gradient varies systematically in their model experiments from 10 $\mathrm{C} \mathrm{km}^{-1}$ at the tip of the wedge to $20 \mathrm{C} \mathrm{km}^{-1}$ in the hinterland. This is caused by high advection rates in the hinterland and the cooling effects of the subducting footwall plate in the foreland. Our results do not include a spatially varying geothermal gradient, and could therefore have underestimated geothermal gradients and overestimated thermochronometer ages for the samples furthest away from the wedge. With such a spatially variable geothermal gradient our model would have required less internal deformation to reproduce the decrease in thermochronometer ages towards the interior of the wedge. However, the magnitude of this effect is difficult to constrain given the lack of subsurface temperature or heat flow data in this part of the Himalayas.

\subsection{Comparison with published numerical models}

Comparison of our results with published thermochronometer model ages by McQuarrie and Ehlers (2015) shows a better fit of the analytical solution to the data (Fig. 11). Note that some of the misfit of the McQuarrie and Ehlers (2015) data may be due to errors introduced by digitizing the model results from their publication. Nonetheless the comparison shows that the new analytical solution fits as well or better than a more sophisticated numerical model that included the activity of individual thrust faults based on balanced cross-sections. This suggests that, for this cross-section, deformation of the wedge can be better represented by uniform deformation.

The sum of the best-fit values of internal deformation and transport along the detachment results in a total shortening rate of $10 \mathrm{~mm} \mathrm{a}^{-1}$. This is comparable to previous findings. Inverse numerical models by Coutand et al. (2014) found the best fit an overall convergence rate of $22 \mathrm{~mm} \mathrm{a}^{-1}$. Roughly half the convergence rate is accommodated by underthrusting, and the convergence taken up by the wedge itself was found to be 10 to $11 \mathrm{~mm} \mathrm{a}^{-1}$, which is equal to our estimate. McQuarrie and Ehlers (2015) found slightly lower total convergence rate of $18 \mathrm{~mm} \mathrm{a}^{-1}$. However, the rate of over and underthrusting were not reported separately. Coutand et al. (2014) and McQuarrie and Ehlers (2015) also included models with variable convergence rates over time. However, in Coutand et al. (2014) the reported misfit for models with variable convergence rates was similar to models with steady convergence rates. McQuarrie and Ehlers (2015) reported a highly variable convergence rate through time. However, the extent to which these inferred changes in convergence rate improved the model fit statistics was not reported. 
https://doi.org/10.5194/se-2021-22

Preprint. Discussion started: 15 March 2021

(c) Author(s) 2021. CC BY 4.0 License.

(c) (i)

In contrast, the good fit of the thermochronometer ages predicted by the steady-state deformation and exhumation equation (Fig. 8) suggests that instead this part of the Himalayas may be in steady-state. This is corroborated by the finding that erosion rates determined on shorter averaging timescales reproduce thermochronological data within error, as expected for steady state landscapes (Ganti et al., 2016). The distributed nature of internal shortening of the wedge is supported by the deep exhumation of Himalayas southern slope as demonstrated by erosional remnants of the once continuous MCT thrust sheet overlying rocks of the Lesser Himalaya (Yin, 2006). This supports the idea that, over long timescales, internal shortening is distributed in nature and does not only occur by large offsets on a few major faults.
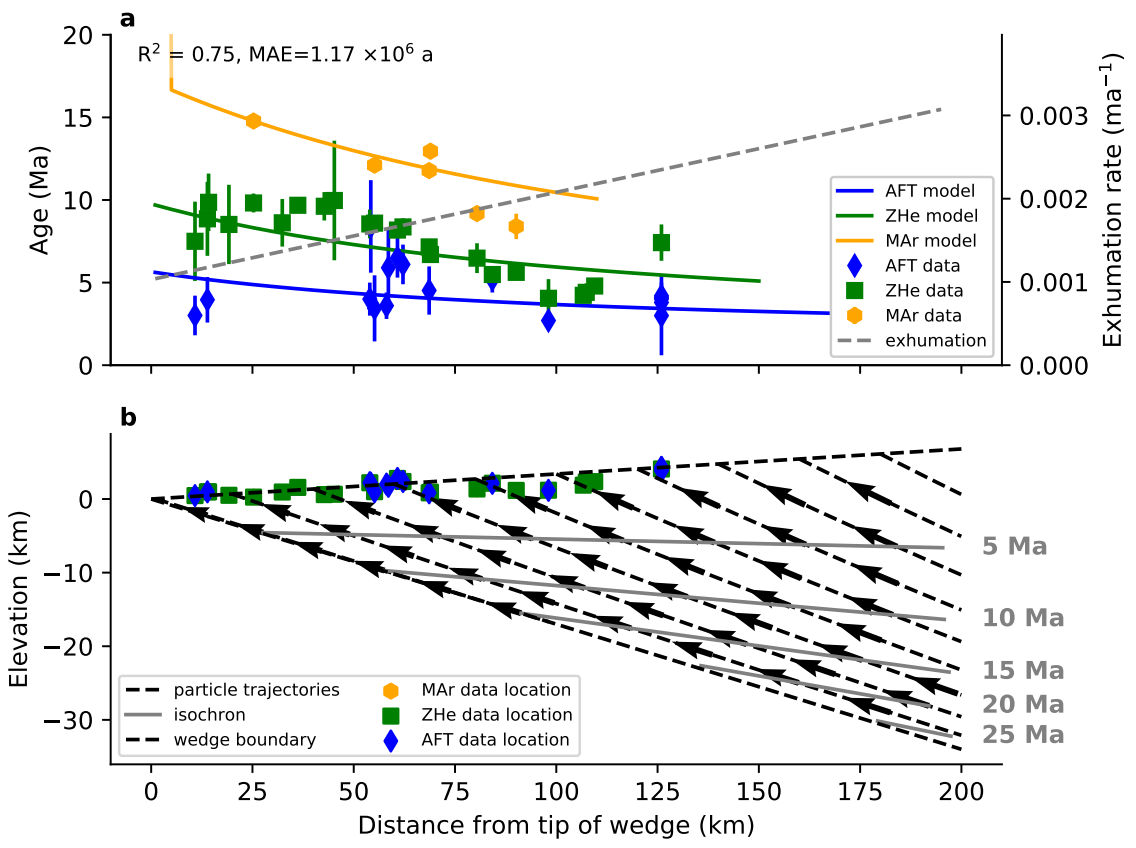

Figure 8. Comparison of calculated thermochronometer ages and published ages for a cross-section in the Himalayas for the best-fit model. Panel a shows calculated and published apatite fission track (AFT), zircon (U-Th)/He (ZHe) and muscovite Ar-Ar ages (MAr), and the exhumation rate at the surface. Panel $\mathrm{b}$ shows the particle trajectories that were used to calculate the cooling ages, along with the isochrons. The calibrated parameter values used for this model run are shown in Table 3. 
https://doi.org/10.5194/se-2021-22

Preprint. Discussion started: 15 March 2021

(c) Author(s) 2021. CC BY 4.0 License.

(c) (i)

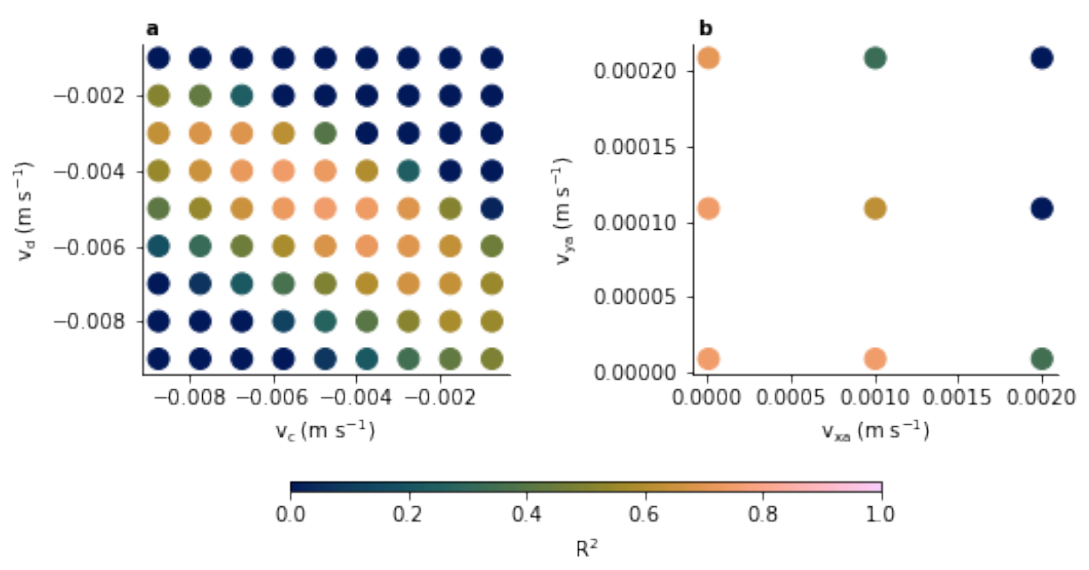

Figure 9. Fit of the calculated thermochronometer ages to the measured ages for a range of values for compression velocity $\left(\mathrm{v}_{\mathrm{c}}\right)$, detachment transport velocity $\left(\mathrm{v}_{\mathrm{d}}\right)$, horizontal and vertical accretion velocity $\left(\mathrm{v}_{\mathrm{xa}}, \mathrm{v}_{\mathrm{ya}}\right)$

Table 3. Calibrated model parameters for the best-fit model shown in Fig. 8 and two additional model experiments shown in Fig 10. The numbers in bold denote calibrated values, non-bold numbers were fixed.

\begin{tabular}{lllll}
\hline parameter & unit & best-fit & experiment 1 & experiment 2 \\
\hline$v_{x a}$ & $m a^{-1}$ & $\mathbf{1 . 7} \times \mathbf{1 0}^{-6}$ & 0 & 0 \\
$v_{y a}$ & $m a^{-1}$ & $\mathbf{0}$ & 0 & 0 \\
$v_{d}$ & $m a^{-1}$ & $\mathbf{- 5 . 0} \times \mathbf{1 0}^{-\mathbf{3}}$ & $\mathbf{- 8 . 8} \times \mathbf{1 0}^{-\mathbf{3}}$ & 0 \\
$v_{c}$ & $m a^{-1}$ & $\mathbf{- 4 . 8} \times \mathbf{1 0}^{-\mathbf{3}}$ & 0 & $\mathbf{- 1 4 . 4} \times \mathbf{1 0}^{-\mathbf{3}}$ \\
\hline
\end{tabular}


https://doi.org/10.5194/se-2021-22

Preprint. Discussion started: 15 March 2021

(c) Author(s) 2021. CC BY 4.0 License.
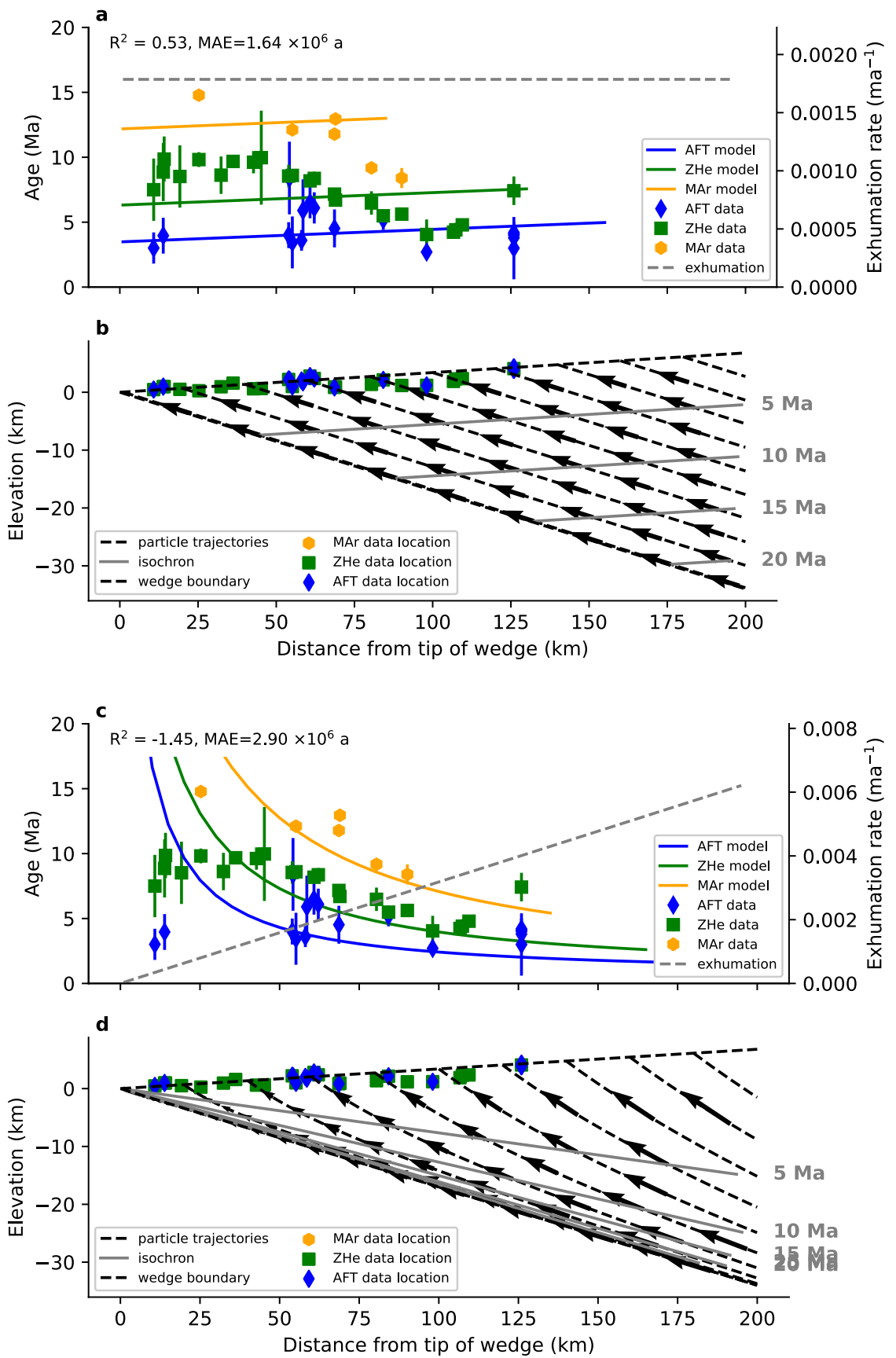

Figure 10. Comparison of calculated themrochronometer ages and published ages for the cross-section in the Himalayas for two model experiments that demonstrate the effect of shortening taken up only by transport along the basal detachment (panels a,b) and shortening taken up only by internal deformation (panels c, d). The parameters for these model runs can be found in Table 3 . 
https://doi.org/10.5194/se-2021-22

Preprint. Discussion started: 15 March 2021

(c) Author(s) 2021. CC BY 4.0 License.

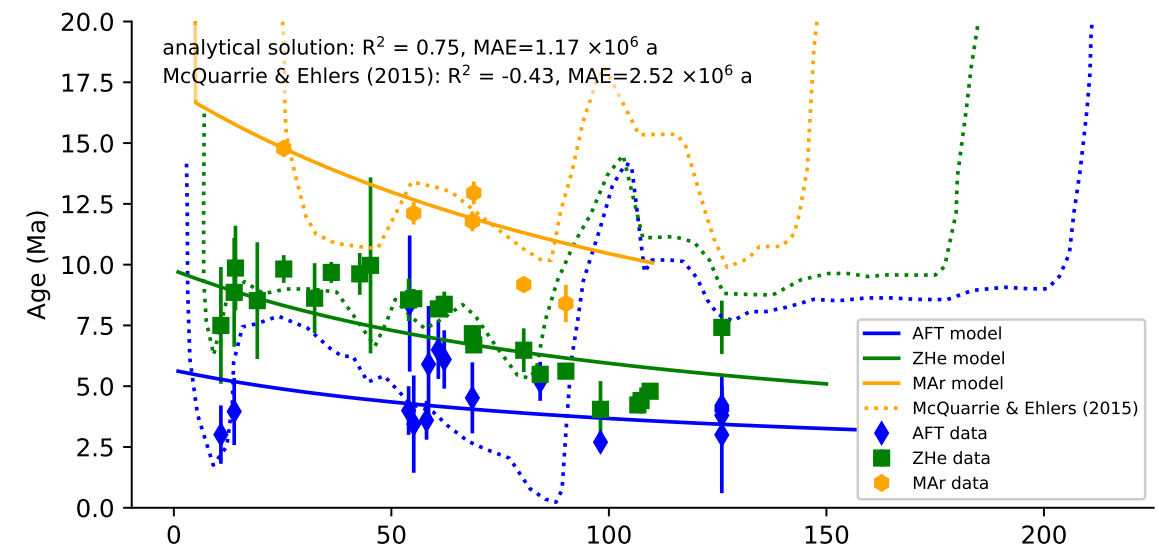

Figure 11. Comparison of published thermochronometer ages, the analytical solution presented in this study (solid lines), and published numerical model results by McQuarrie and Ehlers (2015) (dotted lines). 
https://doi.org/10.5194/se-2021-22

Preprint. Discussion started: 15 March 2021

(c) Author(s) 2021. CC BY 4.0 License.

(c) (i)

We have developed an analytical solution for rock particles trajectories in an orogenic wedge that is in steady-state and that undergoes uniform internal deformation, transport along a basal detachment, frontal accretion and basal accretion. The solution was validated using a numerical solution based on calculated velocity fields and numerical particle tracking. We also derived a simplified solution that provides a good approximation for the upper half of the orogenic wedge, and may therefore be useful to quantify exhumation in the shallow and low-temperature part of orogenic wedges. The solution predicts that exhumation rates follow a curved line along the wedge, with an increase in exhumation rate and a decrease in thermochronometer ages towards the interior of the wedge. The degree of curvature depends on the rate of internal deformation of the wedge. Application of the equation to a published cross-section in the Himalayas show that the equation provides a very good fit to thermochronology data, with an coefficient of determination $\left(R^{2}\right)$ of 0.75 . This indicates that the Himalayas may be in steady-state and that, at a large scale, the exhumation of mature mountain belts may be approximated by a relatively simple model of uniform and steady-state deformation, accretion and transport. The equations enable a direct estimate of deformation and shortening rates from thermochronology data in orogens.

Code availability. Jupyter notebooks that reproduce the workflow and the figures presented in this study have been published at Zenodo (Luijendijk, 2021) and are available at GitHub (https://github.com/ElcoLuijendijk/wedgex). The code is distributed under the GNU General

245 Public License, version 3. The notebook collection include a notebook that reproduces Fig. 5 and 6 that compare the equation to numerical results (https://github.com/ElcoLuijendijk/wedgex/blob/master/model_validation/wedgex_validation.ipynb) and a notebook that can be used to calibrate parameters and compare the results to thermochronometers (https://github.com/ElcoLuijendijk/wedgex/blob/master/wedgex.ipynb), which was used to produce Fig. 8 and 9. Wedgex depends on the Python modules Numpy (Harris et al., 2020), Scipy (Virtanen et al., 2020), Matplotlib (Hunter, 2007), Pandas (McKinney, 2010; Reback et al., 2021), scikit-learn (Pedregosa et al., 2011) and Scientific colour maps (Crameri, 2021). 
https://doi.org/10.5194/se-2021-22

Preprint. Discussion started: 15 March 2021

(c) Author(s) 2021. CC BY 4.0 License.

(c) (i)

\section{Appendix A: Derivation of equations for rock particle velocity}

\section{A1 Velocity due to wedge transport and accretion}

For transport of the wedge along the basal detachment the additional horizontal velocity is constant everywhere and defined as $v_{d}$. The vertical transport velocity is the product of the slope of the basal detachment and the horizontal transport velocity:

$v_{y d}=\beta v_{d}$

Exhumation due to basal and lateral accretion is described by a constant term for the horizontal and vertical velocity of rock particles inside the wedge that represents the lateral and upwards movement of rock particles caused by accretion. These are denoted by $\mathrm{v}_{\mathrm{xa}}$ and $\mathrm{v}_{\mathrm{ya}}$, respectively. The combined horizontal and vertical particle velocity due to transport along a detachment and accretion is denoted as $\mathrm{v}_{\mathrm{xt}}$ and $\mathrm{v}_{\mathrm{yt}}$, respectively:

$v_{y t}=\beta v_{x}+v_{y a}$

\section{A2 Velocity due to internal deformation}

\section{A2.1 Horizontal velocity}

The horizontal velocity due to internal deformation is represented by uniform compression that is assumed to increase linearly from 0 at the left-hand side to $v_{x}=v_{c}$ at the right hand side. This yields the following expression for velocity:

$v_{x}=\frac{x}{L} v_{c}$

\section{A2.2 Vertical velocity at the top of the wedge}

For compression without any volume loss the volume balance of the wedge as shown in Figure 2 can be written as:

$v_{c} H=\int_{0}^{L} v_{y s} L$

270 The velocity at the top of the wedge is assumed to increase linearly from $v_{y s}=0$ at the left hand side to $v_{y s}=v_{y m}$ at the right hand side $(x=L)$ :

$v_{y s}=\frac{x}{L} v_{y m}$ 
https://doi.org/10.5194/se-2021-22

Preprint. Discussion started: 15 March 2021

(c) Author(s) 2021. CC BY 4.0 License.

The area that the wedge extends at the top should be equal to the area that is compressed at the right hand side:

$\frac{1}{2} L v_{y m}=-H v_{c}$

275 which can be combined with the previous eq. to form:

$\frac{L}{x} v_{y s}=-2 \frac{H}{L} v_{c}$

which can be reorganized as to write yield an expression of the particle velocity at the top of the wedge as a function of $x$, the height of the wedge $(H)$, the length of the wedge $(L)$ and the compression velocity $\left(v_{c}\right)$ :

$v_{y s}=-2 \frac{H}{L^{2}} x v_{c}$

\section{A2.3 Vertical velocity inside the wedge}

We assume that the vertical velocity due to wedge compression $\left(\mathrm{v}_{\mathrm{yc}}\right)$ at any point $(\mathrm{x}, \mathrm{y})$ increases linearly from $v_{b}$ at the bottom of the wedge $(\mathrm{y}=\mathrm{b})$ to $v_{y s}$ at the top of the wedge:

$v_{y c}=f v_{y_{b}}+(1-f) v_{y s}$

which can be rearranged as:

$285 v_{y s}=\frac{\left(v_{y c}-(1-f) v_{y b}\right)}{f}$

where $f$ is the relative vertical position of the rock particle in the wedge and is defined as : $f=(y-b) / h$

The equation for $v_{y s}$ that was derived previously is:

$v_{y s}=-2 \frac{H}{L^{2}} x v_{c}$

combining these two equations yields:

$290 \frac{\left(v_{y c}-(1-f) v_{y b}\right)}{f}=-2 \frac{H}{L^{2}} x v_{c}$

which after reorganizing becomes:

$v_{y c}=-2 \frac{H}{L^{2}} x v_{c} f+(1-f) v_{y b}$ 
https://doi.org/10.5194/se-2021-22

Preprint. Discussion started: 15 March 2021

(c) Author(s) 2021. CC BY 4.0 License.

reinserting the original expression for $f=(y-b) / h$ results in:

$v_{y c}=-2 \frac{H}{L^{2}} x v_{c}(y-b) / h+(1-(y-b) / h) v_{y b}$

and inserting $b=\beta x$ and $h=(\alpha-\beta) x=\gamma x$ and $v_{y b}=\beta v_{x b}=\beta \frac{x}{L} v_{c}$ yields:

$v_{y c}=\frac{-2 H x v_{c}}{L^{2}} \frac{y-\beta x}{\gamma x}+\frac{\alpha x-y}{\gamma x} \beta v_{c} x / L$

with $H=(\alpha-\beta) L=\gamma L$ :

$v_{y}=\frac{-2 v_{c}(y-\beta x)}{L}+\frac{(\alpha x-y) \beta v_{c}}{\gamma L}$

which after rearranging yields an expression of the vertical particle velocity due to compression:

$300 v_{y c}=\frac{v_{c}}{L}\left(\left(-2-\frac{\beta}{\alpha-\beta}\right) y+\left(2 \beta+\frac{\alpha \beta}{\alpha-\beta}\right) x\right)$

We simplify this equation by introducing two new terms for the geometry of the wedge:

$\epsilon=\left(-2-\frac{\beta}{\alpha-\beta}\right)$

$\zeta=\left(2 \beta+\frac{\alpha \beta}{\alpha-\beta}\right)$

and introducing the normalized compression velocity $\mathrm{v}_{\mathrm{n}}$ :

$305 v_{n}=\frac{v_{c}}{L}$

Inserting these three new terms into the equation yields:

$v_{y c}=v_{n}(\epsilon y+\zeta x)$

\section{A3 Velocity due to compression, transport and accretion}

The total velocity of rock particles can be found by combining the velocity due to compression (eqs. A4 and A22) and the velocity due to transport (eqs. A2 and A3). For the horizontal velocity this yields:

$v_{x}=v_{x c}+v_{x t}=v_{n} x+v_{x t}$ 
https://doi.org/10.5194/se-2021-22

Preprint. Discussion started: 15 March 2021

(C) Author(s) 2021. CC BY 4.0 License.

And for the vertical component of velocity this yields:

$v_{y}=v_{n}(\epsilon y+\zeta x)+v_{y t}$

\section{Appendix B: Particle trajectories}

\section{B1 Trajectories due to compression}

\section{B1.1 Horizontal particle position}

We integrate the equation for horizontal velocity due to compression of the wedge (eq. A4) to yield an expression for the horizontal particle position over time. The equation for horizontal velocity can be rewritten as:

$$
\frac{\partial x}{\partial t}=v_{n} x
$$

320 Integration of this equation with $x=x_{0}$ at $t=0$ yields:

$$
x=x_{0} e^{v_{n} t}
$$

\section{B1.2 Vertical position}

Taking the equation for vertical velocity due to compression (eq. A22) and replacing $v_{y c}=\frac{\partial y}{\partial t}$ results in:

$$
\frac{\partial y}{\partial t}=v_{n}(\epsilon y+\zeta x)
$$

325 This can be simplified as

$$
\frac{\partial y}{\partial t}=C_{1} y+C_{2} x
$$

where the new constants $\mathrm{C}_{1}$ and $\mathrm{C}_{2}$ are defined as:

$$
C_{1}=v_{n} \epsilon
$$

and 
https://doi.org/10.5194/se-2021-22

Preprint. Discussion started: 15 March 2021

(c) Author(s) 2021. CC BY 4.0 License.

Integration of this equation with boundary condition $y=y_{0}$ at $t=0$, yields an expression for $y$ :

$y=\frac{\zeta v_{n}}{v_{n}-\epsilon v_{n}} x_{0} e^{v_{n} t}+\left(y_{0}-\frac{\zeta v_{n}}{v_{n}-\epsilon v_{n}} x_{0}\right) e^{\epsilon v_{n} t}$

which simplifies to:

$y=\frac{\zeta}{1-\epsilon} x_{0} e^{v_{n} t}+\left(y_{0}-\frac{\zeta}{1-\epsilon} x_{0}\right) e^{\epsilon v_{n} t}$

$y=\beta x_{0} e^{v_{n} t}+\left(y_{0}-\beta x_{0}\right) e^{\epsilon v_{n} t}$

and taking $y_{0}=\alpha x_{0}$ results in:

$y=\beta x_{0} e^{v_{n} t}+(\alpha-\beta) x_{0} e^{\epsilon v_{n} t}$

\section{B2 Trajectories due to transport, compression and accretion}

\section{Horizontal position}

Using the equation for the horizontal velocity of rock particles (eq. A23) and recasting the velocity term as the derivative of position over time results in:

$\frac{\partial x}{\partial t}=v_{n} x+v_{x t}$

Integration of this equation yields:

$345 x=K e^{v_{n} t}-\frac{v_{x t}}{v_{n}}$

Where $\mathrm{K}$ is a constant. Taking $x=x_{0}$ at $t=0$ gives a solution for the horizontal particle position over time:

$x=\left(x_{0}+\frac{v_{x t}}{v_{n}}\right) e^{v_{n} t}-\frac{v_{x t}}{v_{n}}$ 
https://doi.org/10.5194/se-2021-22

Preprint. Discussion started: 15 March 2021

(c) Author(s) 2021. CC BY 4.0 License.

\section{B2.1 Simplified solution for vertical position}

The first solution for the vertical position is a simplified solution, where we take the depth below the surface for compression and for transport and add these two to get an expression for depth over time. For deformation due to compression the vertical position of rock particles over time is given by equation B10. If we define depth due to compression as

$d_{c}=y_{0}-y_{c}=\alpha x_{0}-y_{c}$

we can combine this with eq. B10 to yield:

$d_{c}=\alpha x_{0}-\beta x_{0} e^{v_{n} t}-(\alpha-\beta) x_{0} e^{\epsilon v_{n} t}$

which can be rearranged as:

$d_{c}=(\alpha-\beta) x_{0}\left(e^{v_{n} t}-e^{\epsilon v_{n} t}\right)$

The equation for depth over time due to the transport of rock particles in the wedge follows:

$\frac{\partial y_{t}}{\partial t}=v_{y t}$

Integration of this equation yields:

$y_{d}=y_{0}+v_{y t} t$

rewriting the equation in terms of depth due to transport $\left(d_{t}\right)$ gives:

$d_{t}=-v_{y t} t$

Combining the depth due to transport and due to compression results in an approximate solution for the depth of rock particles (d) over time:

$d=-v_{y t} t+(\alpha-\beta) x_{0}\left(e^{v_{n} t}-e^{\epsilon v_{n} t}\right)$

\section{B2.2 Full solution for vertical position}

Inserting the expression for $\mathrm{x}$ derived earlier (eq. B13) into the solution for the vertical velocity (eq. A24) yields:

$v_{y}=C_{1} y+C_{2}\left(\left(x_{0}+\frac{v_{x t}}{v_{n}}\right) e^{v_{n} t}-\frac{v_{x t}}{v_{n}}\right)+v_{y t}$ 
https://doi.org/10.5194/se-2021-22

Preprint. Discussion started: 15 March 2021

(c) Author(s) 2021. CC BY 4.0 License.

which can be shortened to

$370 \frac{\partial y}{\partial t}=C_{1} y+C_{3} e^{v_{n} t}+C_{4}$

where

$C_{3}=C_{2}\left(x_{0}+\frac{v_{x t}}{v_{n}}\right)$

and

$C_{4}=v_{y t}-C_{2} \frac{v_{x t}}{v_{n}}$

375 which can be recast as:

$C_{4}=v_{y t}-\zeta v_{x t}$

The solution of this integral yields:

$y=(K+\lambda(t)) e^{C_{1} t}$

where $\mathrm{K}$ is a constant and $\lambda(t)$ is:

$380 \lambda(t)=\frac{C_{3}}{v_{n}-C_{1}} e^{\left(v_{n}-C_{1}\right) t}-\frac{C_{4}}{C_{1}} e^{-C_{1} t}$

For the boundary condition $y=y_{0}$ at $t=0$ this yields:

$y=\left(y_{0}-\lambda\left(t_{0}\right)+\lambda(t)\right) e^{C_{1} t}$

with

$\lambda\left(t_{0}\right)=\frac{C_{3}}{v_{n}-C_{1}}-\frac{C_{4}}{C_{1}}$

Reinserting the expressions for the constants $\mathrm{C}_{1}, \mathrm{C}_{2}, \mathrm{C}_{3}$ and $\mathrm{C}_{4}$ yields the following equation:

$y=\left(\alpha x_{0}+\beta\left(x_{0}+\frac{v_{x t}}{v_{n}}\right)\left(e^{v_{n}(1-\epsilon) t}-1\right)-\frac{v_{y t}-\zeta v_{x t}}{v_{n} \epsilon}\left(e^{-v_{n} \epsilon t}-1\right)\right) e^{v_{n} \epsilon t}$ 
https://doi.org/10.5194/se-2021-22

Preprint. Discussion started: 15 March 2021

(C) Author(s) 2021. CC BY 4.0 License.

(c) (i)

Author contributions. EL conceived the idea after JK showed that straight lines often fit thermochronometer age profiles in orogens relatively well. EL and LB derived the equations. EL led the model experiments and the writing. CvH and SL drafted figure 1 and 2 . All authors contributed to the discussion of the results and writing the manuscript

Competing interests. The authors declare that no competing interest are present.

Acknowledgements. EL, SL, CvH and JK acknowledge funding by DFG project 363551335, which is part of the special priority program "Mountain Building Processes in 4D". LB is partially funded by the DFG Research Training Group 2491 "Fourier Analysis and Spectral Theory". 
https://doi.org/10.5194/se-2021-22

Preprint. Discussion started: 15 March 2021

(c) Author(s) 2021. CC BY 4.0 License.

(c) (i)

\section{References}

Adams, B. A., Hodges, K. V., van Soest, M. C., and Whipple, K. X.: Evidence for pliocene-quaternary normal faulting in the hinterland of the bhutan himalaya, Lithosphere, 5, 438-449, https://doi.org/10.1130/L277.1, 2013.

Braun, J., van der Beek, P., Valla, P., Robert, X., Herman, F., Glotzbach, C., Pedersen, V., Perry, C., Simon-Labric, T., and Prigent, C.: Quantifying rates of landscape evolution and tectonic processes by thermochronology and numerical modeling of crustal heat transport using PECUBE, Tectonophysics, 524-525, 1-28, https://doi.org/10.1016/j.tecto.2011.12.035, 2012.

Buiter, S. J.: A review of brittle compressional wedge models, Tectonophysics, 530-531, 1-17, https://doi.org/10.1016/j.tecto.2011.12.018, 2012.

Chapple, W. M.: Mechanics of thin-skinned fold-and-thrust belts, Geological Society of America Bulletin, pp. 1189-1198, 1978.

Coutand, I., Grujic, D. M. W. J. D., Bernet, M., Fellin, M. G., Bookhagen, B., Landry, K. R., Ghalley, S. K., and Duncan, C.: Geometry and kinematics of the Main Himalayan Thrust and Neogene crustal exhumation in the Bhutanese Himalaya derived from inversion of multithermochronologic data, Journal of Geophysical Research: Solid Earth, pp. 1-36, https://doi.org/10.1002/2013JB010891, 2014.

Crameri, F.: Scientific colour maps, https://doi.org/10.5281/zenodo.4491293, https://doi.org/10.5281/zenodo.4491293, 2021.

Dahlen, F. A., Suppe, J., and Davis, D.: Mechanics of Fold-and-Thrust Belts and Accretionary Wedges: Cohesive Coulomb Theory., Journal of Geophysical Research, 89, 10 087-10 101, https://doi.org/10.1029/JB089iB12p10087, 1984.

Davis, D., Suppe, J., and Dahlen, F.: Mechanics of Fold-and-Thrust Belts and Accretionary Wedges, Journal of geophysical research, 88, 1153-1172, 1983.

Dodson, M. H.: Closure temperature in cooling geochronological and petrological systems, Contributions to Mineralogy and Petrology, 40, 259-274, https://doi.org/10.1007/BF00373790, 1973.

Erdös, Z., Van Der Beek, P., and Huismans, R. S.: Evaluating balanced section restoration with thermochronology data: A case study from the Central Pyrenees, Tectonics, 33, 617-634, https://doi.org/10.1002/2013TC003481, 2014.

Fox, M., Herman, F., Willett, S. D., and May, D. A.: A linear inversion method to infer exhumation rates in space and time from thermochronometric data, Earth Surface Dynamics, 2, 47-65, https://doi.org/10.5194/esurf-2-47-2014, 2014.

Ganti, V., von Hagke, C., Scherler, D., Lamb, M. P., Fischer, W. W., and Avouac, J.-P.: Time scale bias in erosion rates of glaciated landscapes, Science Advances, 2, https://doi.org/10.1126/sciadv.1600204, 2016.

Grujic, D., Coutand, I., Bookhagen, B., Bonnet, S., Blythe, A., and Duncan, C.: Climatic forcing of erosion, landscape, and tectonics in the Bhutan Himalayas, Geology, 34, 801-804, https://doi.org/10.1130/G22648.1, 2006.

Harris, C. R., Millman, K. J., van der Walt, S. J., Gommers, R., Virtanen, P., Cournapeau, D., Wieser, E., Taylor, J., Berg, S., Smith, N. J., Kern, R., Picus, M., Hoyer, S., van Kerkwijk, M. H., Brett, M., Haldane, A., del Río, J. F., Wiebe, M., Peterson, P., Gérard-Marchant, P., Sheppard, K., Reddy, T., Weckesser, W., Abbasi, H., Gohlke, C., and Oliphant, T. E.: Array programming with NumPy, Nature, 585, 357-362, https://doi.org/10.1038/s41586-020-2649-2, 2020.

Herman, F., Copeland, P., Avouac, J.-P., Bollinger, L., Mahéo, G., Le Fort, P., Rai, S., Foster, D., Pêcher, A., Stüwe, K., and Henry, P.: Exhumation, crustal deformation, and thermal structure of the Nepal Himalaya derived from the inversion of thermochronological and thermobarometric data and modeling of the topography, Journal of Geophysical Research: Solid Earth, 115, https://doi.org/https://doi.org/10.1029/2008JB006126, https://doi.org/10.1029/2008JB006126, 2010.

Hunter, J. D.: Matplotlib: A 2D graphics environment, Computing in Science \& Engineering, 9, 90-95, https://doi.org/10.1109/MCSE.2007.55, 2007. 
https://doi.org/10.5194/se-2021-22

Preprint. Discussion started: 15 March 2021

(c) Author(s) 2021. CC BY 4.0 License.

(c) (i)

Lock, J. and Willett, S.: Low-temperature thermochronometric ages in fold-and-thrust belts, Tectonophysics, 456, 147-162, https://doi.org/10.1016/j.tecto.2008.03.007, 2008.

Long, S. P., McQuarrie, N., Tobgay, T., Coutand, I., Cooper, F. J., Reiners, P. W., Wartho, J. A., and Hodges, K. V.: Variable shortening rates in the eastern Himalayan thrust belt, Bhutan: Insights from multiple thermochronologic and geochronologic data sets tied to kinematic reconstructions, Tectonics, 31, https://doi.org/10.1029/2012TC003155, 2012.

Luijendijk, E.: wedgex: calculate the exhumation of an orogenic wedge, https://doi.org/10.5281/zenodo.4571576, https://doi.org/10.5281/ zenodo.4571576, 2021.

McKinney, W.: Data Structures for Statistical Computing in Python, in: Proceedings of the 9th Python in Science Conference, edited by van der Walt, S. and Millman, J., pp. 56-61, https://doi.org/10.25080/Majora-92bf1922-00a, 2010.

McQuarrie, N. and Ehlers, T. A.: Influence of thrust belt geometry and shortening rate on thermochronometer cooling ages: Insights from thermokinematic and erosion modeling of the Bhutan Himalaya, Tectonics, 34, 1055-1079, https://doi.org/10.1002/2014TC003783, 2015.

McQuarrie, N. and Ehlers, T. A.: Techniques for understanding fold-and-thrust belt kinematics and thermal evolution, in: Linkages and Feedbacks in Orogenic Systems, edited by Law, R., Thigpen, J., Merschat, A., and Stowell, H., vol. 1213, pp. 25-54, Geological Society of America, 213 edn., https://doi.org/10.1130/2017.1213(02), 2018.

Nelder, J. A. and Mead, R.: A Simplex Method for Function Minimization, The Computer Journal, 7, 308-313, http://comjnl.oxfordjournals. org/cgi/content/abstract/7/4/308, 1965.

Pedregosa, F., Varoquaux, G., Gramfort, A., Michel, V., Thirion, B., Grisel, O., Blondel, M., Prettenhofer, P., Weiss, R., Dubourg, V., and Others: Scikit-learn: Machine learning in Python, Journal of machine learning research, 12, 2825-2830, 2011.

Platt, J. P.: Dynamics of orogenic wedges and the uplift of high-pressure metamorphic rocks., Geological Society of America Bulletin, 97, 1037-1053, https://doi.org/10.1130/0016-7606(1986)97<1037:DOOWAT>2.0.CO;2, 1986.

Reback, J., McKinney, W., Jbrockmendel, den Bossche, J. V., Augspurger, T., Cloud, P., Gfyoung, Hawkins, S., Sinhrks, Roeschke, M., Klein, A., Petersen, T., Tratner, J., She, C., Ayd, W., Naveh, S., Garcia, M., Schendel, J., Patrick, Hayden, A., Saxton, D., Jancauskas, V., McMaster, A., Gorelli, M., Battiston, P., Seabold, S., Dong, K., Chris-b1, H-vetinari, and Hoyer, S.: pandas-dev/pandas: Pandas 1.2.2, https://doi.org/10.5281/zenodo.4524629, 2021.

Reiners, P. W. and Brandon, M. T.: Using thermochronology to understand orogenic erosion, Annual Review of Earth and Planetary Sciences, 34, 419-466, 2006.

Robert, X., van der Beek, P., Braun, J., Perry, C., and Mugnier, J.-L.: Control of detachment geometry on lateral variations in exhumation rates in the Himalaya: Insights from low-temperature thermochronology and numerical modeling, Journal of Geophysical Research: Solid Earth, 116, https://doi.org/https://doi.org/10.1029/2010JB007893, 2011.

ter Voorde, M., de Bruijne, C. H., Cloetingh, S. A., and Andriessen, P. A.: Thermal consequences of thrust faulting: Simultaneous versus successive fault activation and exhumation, Earth and Planetary Science Letters, 223, 395-413, https://doi.org/10.1016/j.epsl.2004.04.026, 2004.

Van Gool, J. A. and Cawood, P. A.: Frontal vs. basal accretion and contrasting particle paths in metamorphic thrust belts, Geology, 22, 51-54, https://doi.org/10.1130/0091-7613(1994)022<0051:FVBAAC>2.3.CO;2, 1994.

465 Virtanen, P., Gommers, R., Oliphant, T. E., Haberland, M., Reddy, T., Cournapeau, D., Burovski, E., Peterson, P., Weckesser, W., Bright, J., van der Walt, S. J., Brett, M., Wilson, J., Millman, K. J., Mayorov, N., Nelson, A. R. J., Jones, E., Kern, R., Larson, E., Carey, C. J., Polat, I., Feng, Y., Moore, E. W., VanderPlas, J., Laxalde, D., Perktold, J., Cimrman, R., Henriksen, I., Quintero, E. A., Harris, C. R., Archibald, A. M., Ribeiro, A. H., Pedregosa, F., van Mulbregt, P., Vijaykumar, A., Bardelli, A. P., Rothberg, A., Hilboll, A., Kloeckner, 
https://doi.org/10.5194/se-2021-22

Preprint. Discussion started: 15 March 2021

(c) Author(s) 2021. CC BY 4.0 License.

(c) (1)

A., Scopatz, A., Lee, A., Rokem, A., Woods, C. N., Fulton, C., Masson, C., Häggström, C., Fitzgerald, C., Nicholson, D. A., Hagen, D. R., Pasechnik, D. V., Olivetti, E., Martin, E., Wieser, E., Silva, F., Lenders, F., Wilhelm, F., Young, G., Price, G. A., Ingold, G.-L., Allen, G. E., Lee, G. R., Audren, H., Probst, I., Dietrich, J. P., Silterra, J., Webber, J. T., Slavič, J., Nothman, J., Buchner, J., Kulick, J., Schönberger, J. L., de Miranda Cardoso, J. V., Reimer, J., Harrington, J., Rodríguez, J. L. C., Nunez-Iglesias, J., Kuczynski, J., Tritz, K., Thoma, M., Newville, M., Kümmerer, M., Bolingbroke, M., Tartre, M., Pak, M., Smith, N. J., Nowaczyk, N., Shebanov, N., Pavlyk, O., Brodtkorb, P. A., Lee, P., McGibbon, R. T., Feldbauer, R., Lewis, S., Tygier, S., Sievert, S., Vigna, S., Peterson, S., More, S., Pudlik, T., Oshima, T., Pingel, T. J., Robitaille, T. P., Spura, T., Jones, T. R., Cera, T., Leslie, T., Zito, T., Krauss, T., Upadhyay, U., Halchenko, Y. O., Vázquez-Baeza, Y., and Contributors, S. .: SciPy 1.0: fundamental algorithms for scientific computing in Python, Nature Methods, https://doi.org/10.1038/s41592-019-0686-2, 2020.

Vogel, J.: Investigation of groundwater flow with radiocarbon, Isotopes in Hydrology, I, 355-369, 1967.

Yin, A.: Cenozoic tectonic evolution of the Himalayan orogen as constrained by along-strike variation of structural geometry, exhumation history, and foreland sedimentation, Earth-Science Reviews, 76, 1-131, https://doi.org/10.1016/j.earscirev.2005.05.004, 2006. 